\title{
Gastrojejunal anastomosis stricture after laparoscopic gastric bypass. Our experience with 62 patients
}

\author{
A. Campillo-Soto ${ }^{1}$, J. A. Torralba-Martínez ${ }^{1}$, J. G. Martín-Lorenzo ${ }^{1}$, R. Lirón-Ruiz ${ }^{1}$, M. Bento-Gerard ${ }^{2}$, \\ E. Pérez-Cuadrado ${ }^{3}$ and J. L. Aguayo-Albasini ${ }^{1}$
}

Services of ${ }^{1}$ General Surgery, ${ }^{2}$ Anesthesia, and ${ }^{3}$ Digestive Diseases. Hospital General Universitario J. M. Morales

Meseguer. Murcia, Spain

\begin{abstract}
Objective: gastrojejunal stricture (GYS), not only is a common complication after laparoscopic gastric bypass (LGBP), but its frequency is about $15 \%$ according to bibliography. Our aim is to present our experience after 62 LGBP.

Patients and method: from January 2004 to September2006, we performed 62 consecutive laparoscopic gastric bypass (Wittgrove's technique). The gastrojejunal anastomosis is performed with auto suture material type CEAA No 21 termino-lateral (ILS, Ethicon). In 4 cases (6.45\%) was converted to laparotomy, perform the anastomosis in the same way. Monitoring has a range of 3-35 months, conducted in 61 patients because one patient died of pulmonary thromboembolism in the immediate postoperative period after reoperation, after two weeks of gastric bypass, by necrosis of a small fragment of the remnant gastric. In all patients with persistent feeding intolerance were performed barium transit and/or gastroscopy. When gastrojejunal stricture showed proceeded to endoscopic pneumatic dilation (recommending dilate the anastomosis to a maximum $1.5 \mathrm{~cm}$ ).

Results: five cases (8.1\%) developed a gastrojejunal stricture, in 4 of these cases the initial diagnosis was made by barium transit and in 1 case by endoscopy. Two patients had a history of digestive bleeding that required endoscopic sclerosis of the bleeding lesion (circumferentially sclerosis within 48 hours of surgery and sclerosis of bleeding points). All cases were resolved by endoscopic dilatation. At follow-up has not been detected re-stricture.

Conclusion: Clinically, gastrojejunal stricture results in a progressive oral intolerance, revealing stenosis between 1 and 3 months postoperatively. The situations of sclerosis of the bleeding lesions favor, especially in cases of extensive sclerosis. In cases of suspected barium transit offers us a high diagnostic yield. Endoscopic dilatation resolved, so far, all cases.
\end{abstract}

Key words: Stricture after gastric bypass. Morbid obesity. Complications and gastric bypass.

Received: 03-03-09.

Accepted: $10-11-09$

Correspondence: Álvaro Campillo Soto. Servicio de Cirugía General y Digestiva. $3^{\text {a }}$ planta. Hospital General Universitario J. M. Morales Meseguer. C/ Marqués de los Vélez, s/n. 30008 Murcia, Spain. e-mail: alvaroalcubo@yahoo.es
Campillo-Soto A, Torralba-Martínez JA, Martín-Lorenzo JG, Lirón-Ruiz R, Bento-Gerard M, Pérez-Cuadrado E, Aguayo-Albasini JL. Gastrojejunal anastomosis stricture after laparoscopic gastric bypass. Our experience with 62 patients. Rev Esp Enferm Dig 2010; 102: 187-192.

\section{INTRODUCTION}

Surgical treatment of morbid obesity is the only effective long-term therapy to achieve and maintain over time significant weight loss. Among the techniques used in the surgical treatment of obesity, gastric bypass is the most used (1). Although the benefits and complications is quite favorable, the most frequence complications are dehiscences and bleeding with a constant incidence in different series $(2,3)$. On the gastrojejunal anastomosis stricture its incidence is variable, occurring between 1 and $15 \%$ of patients, according to series $(4,5)$.

The aim of this paper is to present the incidence of this complication and its management, in our series of 62 patients operated for LGBP.

\section{PATIENTS AND METHODS}

In the period between January 2004 and September 2006, 62 patients underwent LGB (Wittgrove technique) (6) in the General Surgery Department, Hospital General Universitario J. M. Morales Meseguer de Murcia. The 62 patients were divided into 25 males and 37 females with a mean age of 41 years (range: $25-60$ years). The indications for the LGB were patients with adequate psychological profile in whom conservative treatment has failed monitored: a) body mass index (BMI) equal to or greater than $40 \mathrm{~kg} / \mathrm{m}^{2}$; or b) BMI $=35$ if comorbidities are associated with greater. 
The candidates for bariatric surgery patients are sent to queries Endocrinology. If they meet the inclusion criteria and following assessment by the Psychiatry Department, are forwarded to the Department of General Surgery, some with $\mathrm{BMI}>55$ and severe concomitant disease, digestive refer to valuation of temporary placement of intragastric balloon. Since the surgery consultation is coordinated surgical risk assessment by the anesthesia and sometimes with the participation of cardiology and respiratory medicine, and after signing an informed consent specific to this technique, were operated by the same group of surgeons with special dedication this pathology. General anesthesia was performed and specific monitoring LGB. In all cases, after surgery was performed on postoperative intensive care unit for 24 hours. Was performed and thromboembolic prophylaxis, and daily tracking of the procedure, both from the standpoint of medical and nursing and nutrition in our clinical pathway for the LGB.

GYS was performed with autosuture material type CEAA No 21 termino-lateral (ILS, Ethicon ${ }^{\circledR}$ ), after checking the anastomotic leakage occurred in all cases. In cases of conversion to laparotomy was performed the same procedure. The analysis of the results was done by "intention-to-treat" is therefore included in the study of patients converted to laparotomy.

Following discharge, patients were reviewed and followed up in outpatient surgery at first postoperative month and then regularly every 3 months.

We designed a protocol for prospective data collection and monitoring including: details of affiliation, personal history, BMI, type of surgery, causes of conversion to laparotomy, early and late complications, days of hospitalization, mortality and its causes.

The monitoring of patients was performed prospectively from the immediate postoperative period until the patient's death or end-point of the study (September 2006). In all patients with persistent feeding intolerance was performed barium transit and/or gastroscopy. When gastrojejunal stenosis showed proceeded to endoscopic pneumatic dilation (recommending dilate the gastrojejunal stricture to a maximum $1.5 \mathrm{~cm}$ ).

\section{RESULTS}

Between January 2004 and September 2006, 62 LGB were performed in our department of surgery. Sixty-one patients were followed during the study period with an mean of 24 months (range: 3-35 months). One patient died of massive pulmonary thromboembolism in the immediate postoperative period after reoperation.

Five patients $(8.1 \%)$ developed a gastrojejunal stricture. As the clinic at $100 \%$ of cases oral intolerance progressively between 1 and 3 months postoperatively in 4 of them the initial diagnosis was made by barium transit and in the remaining case by endoscopy. Two patients had a history of upper gastrointestinal bleeding (UGIB) who required endoscopic sclerosis of the bleeding lesion (circumferentially sclerosis within 48 hours of surgery and sclerosis of bleeding points). All cases were resolved by endoscopic dilatation, specifying in two cases $(40 \%)$, two sessions of dilation and the remaining $3(60 \%)$ one. Throughout the following patients were not detected restricture or new cases diagnosed. There was no mortality related to this complication.

\section{DISCUSSION}

Proper management of morbid obesity requires creation of a unit overspecialized in which to be involved general surgeons, psychiatrists, digestion, anesthesiologists, endocrinologists and nutritionists, as each case requires a detailed study to determine the best therapeutic option $(7,8)$. Moreover, in cases with surgical indication and postoperative follow-up multidisciplinary is very important for early detection and treatment of complications.

The LGB is the most widely used, with relatively few complications and well managed. Anastomotic dehiscence $(1-2 \%)(3,9)$ and gastrointestinal bleeding (3-6\%) are highlight complications of LGB $(2,10)$. Gastrojejunal stricture is a complication variable depending on the series $(1-15 \%)(4,5)$, the stricture can be functional or anatomical, being the frequency of each variable equally. In our series we had an interim rate of stricture $(8 \%)$ compared with those published in the literature. The diagnosis of these lesions is based on clinical suspicion for any patient operated with LGB with digestive difficulties and persistent feeding intolerance. The clinical presentation of these lesions from the first postoperative month is because during the first 4-6 weeks the patients received a liquid diet LGB, with the addition of semi-solid foods started from the 1-2 months postoperative (11). Its diagnosis is confirmed with a transit barium or endoscopy. The performance of barium transit is the speed advantage in their construction and ready availability as a disadvantage and that simply is diagnostic. While endoscopy is diagnostic, therapeutic, and its lower handicap accessibility or delay in make it (10). In our series, $80 \%$ of cases were diagnosed by barium transit, endoscopy being used in the remaining case $(20 \%)$.

The treatment is endoscopic pneumatic dilation one or several sessions, and their results excellent, long-term, regarding the absence of complications and failures, as reflected in surgical papers $(5,9,12)$. Our results on treatment are consistent with this last statement, because we have not had any complications or failure in treating these patients.

The fact that there are 2 cases $(40 \%)$ with history of UGIB during the immediate postoperative period, which have required circumferential endoscopic electrocoagulation, suggests the hypothesis that circumferential coagu- 
lation may be a risk factor for subsequent stenosis as a result of the reaction secondary-inflammatory scar. Because we have not found this association in the literature, we believe that further studies are needed to reach solid conclusions.

Among the factors favoring the development of stenosis include technical factors: the performance of smallcaliber anastomosis (in order to avoid the rapid gastric emptying of the bag) and a mechanical factor or apparatus: the circular staple line autosuture material $(5,9)$. Gonzalez et al. (13) published a comparative study of the circular mechanical anastomosis versus manual anastomosis, noting a significant increase in the group with stenosis anastomosis with circular stapler (31 vs. 3\%). Other authors have confirmed these results, Nguyen et al. (3) have reported a $11.4 \%$ stenosis with circular mechanical anastomosis, compared with $4.9 \%$ published by Higa et al. (14) with manual anastomosis. In another study, Nguyen showed a higher incidence of stenosis when performed with circular stapler $21 \mathrm{~mm}$ in diameter $(26.8 \%$ of cases) than when performed with a diameter of $25 \mathrm{~mm}$ (7.6\%) without differences were seen between the weight loss between both groups (15). In terms of linear mechanical anastomosis have been published stenosis rates between 4 and $7 \%(16,17)$, very similar results to those of manual anastomosis. In our series we had a very similar percentage stenosis in the series with a linear stapler or manual $(8 \%)$, and we believe that our technique with circular mechanical anastomosis is valid and meets the highest standards published.

\section{REFERENCES}

1. IBSR, IBSR 2000-2001 Winter Pooled Report. Iowa City: Internacional Bariatric Surgery Registry; 2001. p. 19.

2. Livingston EH, Huerta S, Arthur D, Lee S, De Shields S, Heber D.
Male gender is a predictor of morbidity and age a predictor of mortality for patients undergoing gastric bypass surgery. Ann Surg 2002; 236: $576-82$

3. Nguyen NT, Goldman Ch, Rosenquist CJ, Arango A, Cole CJ, Lee SJ. Laparoscopic versus open gastric bypass a randomised study of outcomes, quality of life and costs. Ann Surg 2001; 234: 279-91.

4. Fobi MAL, Lee H, Holness R, Cabinda DG. Gastric bypass operation for obesity. World J Surg 1998; 22: 925-35.

5. Kellum JM, De Maria EJ, Sugerman HJ. The surgical treatment of morbid obesity. Curr Probl Surg 1998; 35: 795-858.

6. Wittgrove AC, Clark GW. Laparoscopic gastric bypass, Roux-en-Y500 patients: technique and results, with 3-60 month follow-up. Obes Surg 2000; 10: 233-9.

7. Chacón S, Esteban P, Campillo-Soto A, Del Pozo P, Torrella E, Shanabo J, et al. Endoscopic approach to bariatric surgery. The role of double-balloon enteroscopy. Rev Esp Enferm Dig 2008; 100(6): 365-6.

8. Benito de Benito LM, Aguado Romo R. More on sedation in digestive endoscopy. Rev Esp Enferm Dig 2009; 101(7): 483-91.

9. Brolin RE. Gastric bypass. Surg Clin N Am 2001; 81: 1077-95.

10. Diez del Val I, Martínez-Blázquez C, Valencia-Cortejoso J, SierraEsteban V, Vitores-López JM. Bypass gástrico. Cir Esp 2004; 75: 244-50.

11. García-Lorda P, Hernández-González M, Blanco-Blasco JS, Figueredo R, Sabench-Pereferrer F, Balanza-Roure R, et al. Seguimiento postoperatorio de la obesidad mórbida: aspectos quirúrgicos y nutricionales. Cir Esp 2004; 75: 305-11.

12. Sebastián JJ, Peña E, Blas JM, Ceña G, Díez M. Management of gastric outlet obstruction after esophagectomy using forced pyloric dilation. Rev Esp Enferm Dig 2008; 100(9): 594-5.

13. González R, Lin E, Venkastesh KR. Gastroyeyunostomy during laparoscopic gastric bypass. Analisis of 3 techniques. Arch Surg 2003; 138: 181-4.

14. Higa KD, Boone KB, Ho T, Davies OG. Laparoscopic Roux en Y gastric bypass for morbid obesity: technique and preliminary results of our first 400 patients. Arch Surg 2000; 135: 1029-33.

15. Nguyen NT, Rivers R, Stevens M. Incidence and outcome of anastomosis stricture after laparoscopic gastric bypass. Proceeding of Encuentro anual de la Sociedad de Cirugía del Tracto Alimentario. Orlando, FA. USA. Mayo 18-21. 2003.

16. De Maria EJ, Sugerman HJ, Kellum JM. Results of 281 consecutive total laparoscopic Roux en Y gastric bypasses to treat morbid obesity. Ann Surg 2002; 235: 640-7.

17. Schauer PR, Ikramuddin S, Gourash W. Outcomes after laparoscopic en Y gastric bypass for morbid obesity. Ann Surg 2000; 232: 515-29. 